\title{
Efeitos do teor de carboidratos solúveis sobre as características da silagem de cana-de-açúcar
}

\author{
Estela Jorge Alves da Silva², Laura Maria Oliveira Borgatti ${ }^{3}$, Paula Marques Meyer ${ }^{4}$, Carolina \\ Tobias Marino ${ }^{5}$, Paulo Henrique Mazza Rodrigues ${ }^{6}$
}

${ }_{1}$ Projeto financiado pela Fundação de Amparo à Pesquisa do Estado de São Paulo (FAPESP)

2 Pós-graduando do Departamento de Nutrição e Produção Animal - FMVZ/USP, Campus de Pirassununga-SP.

3 Pós-doutoranda do Departamento de Nutrição e Produção Animal - FMVZIUSP. Campus de Pirassununga-SP.

${ }^{4}$ Instituto Brasileiro de Geografia e Estatística-IBGE.

5 Pós-graduanda da Faculdade de Medicina Veterinária e Zootecnia/UNESP, Campus de Botucatu-SP

${ }^{6}$ Departamento de Nutrição e Produção Animal, FMVZ/USP, Av. Duque de Caxias Norte, 225, CEP: 13630-000, Pirassununga-SP.

RESUMO - Objetivou-se quantificar na cana-de-açúcar o teor de carboidratos solúveis (CHOs) que anula a produção de etanol e avaliar os efeitos desses carboidratos sobre o valor nutritivo e outras características fermentativas da silagem de canade-açúcar. Utilizou-se o delineamento inteiramente casualizado com três tratamentos, cada um com quatro repetições. Os tratamentos consistiram da retirada total do caldo da cana-de-açúcar, por meio de prensagem, e de sua reconstituição (0, 50 ou $100 \%$ ) à cana. No nível de $50 \%$ de reconstituição, o caldo foi adicionado à cana juntamente com $50 \%$ de água e, no nível $0 \%$, adicionou-se $100 \%$ de água à cana. A restituição resultou em concentrações de 41,6; 34,0 e 23,0\% de carboidratos solúveis na matéria seca (MS). O material foi ensilado em 12 silos experimentais confeccionados a partir de baldes plásticos. A abertura dos silos foi realizada 85 dias após a ensilagem, quando foram determinados os teores dos ácidos orgânicos e a composição química das silagens. A retirada de carboidratos solúveis da cana-de-açúcar teve efeito linear decrescente sobre os teores de matéria seca, o teor de carboidratos solúveis e a digestibilidade in vitro da matéria seca (DIVMS) das silagens, no entanto, ocasionou aumento dos teores de fibra detergente ácido (FDA), fibra detergente neutro (FDN) e lignina. Observou-se efeito linear decrescente da retirada dos carboidratos solúveis sobre os teores de etanol e ácidos lático e butírico e as perdas de matéria seca das silagens. Não se observaram efeitos de tratamentos sobre os dados de estabilidade aeróbia. A produção de etanol seria nula se a cana-de-açúcar contivesse apenas $12,4 \%$ de CHOs com base na matéria seca (MS).

Palavras-chave: ensilagem, etanol, fermentação, forragem, valor nutritivo

\section{Effect of water soluble carbohydrates on characteristics of sugarcane silage}

\begin{abstract}
The objectives of this trial were to quantify the water soluble carbohydrates (WSC) concentration present in sugarcane that nullifies ethanol production, and to evaluate the effects of WSC content on nutritive value and other fermentative characteristics of sugarcane silage. A completely randomized design was used with three treatments and four repetitions per treatment. Sugarcane was squeezed in order to remove juice. In the first treatment, juice was totally added back to sugarcane $(100 \%)$. In the second treatment, only $50 \%$ of the juice was added back to sugarcane, along with $50 \%$ of water. In the third, $100 \%$ of water was added, with no addition of juice. Treatments resulted in WSC concentrations of 41.6, 34.0, and $23.0 \%$ on dry matter basis. The material was ensiled in 12 laboratory silos (plastic buckets). Silos were opened 85 days after ensiling, when organic acids concentration and chemical composition of silages were determined. Withdrawal of sugarcane WSC resulted in negative linear effects on dry matter, WSC concentration, and in vitro digestibility of dry matter, but with linear increase for acid detergent fiber, neutral detergent fiber, and lignin concentration. Considering the fermentation data, there was linear decrease for dry matter losses, lactic and butyric acids, and ethanol concentration. No treatment effect on aerobic stability data was observed. Ethanol production would be null if sugarcane had only $12.4 \%$ of water-soluble carbohydrates on dry matter basis.
\end{abstract}

Key Words: ensiling, ethanol, fermentation, forage, nutritive value

\section{Introdução}

A ensilagem da cana-de-açúcar é realizada para diminuir os custos operacionais, poupar o trabalho do manejo diário do canavial e evitar perdas com possíveis geadas e queimadas. Entretanto, a cana ensilada possui altas concentrações de etanol, em virtude do alto teor de carboidratos solúveis e da população de leveduras, que convertem açúcares a etanol, 
$\mathrm{CO}_{2}$ e água, diminuindo o teor de carboidratos solúveis e aumentando os componentes da parede celular e as perdas de matéria seca (MS), o que prejudica a qualidade e o valor nutritivo da silagem (Alli et al., 1983). Na tentativa de diminuir a produção de álcool, pesquisadores têm utilizado aditivos químicos e microbiológicos na ensilagem dessa forrageira.

Freitas et al. (2006), avaliando as características da silagem de cana-de-açúcar tratada com inoculante bacteriano ou hidróxido de sódio ou acrescida de resíduo da colheita de soja, observaram que o resíduo da colheita de soja melhorou a qualidade nutritiva e reduziu as perdas de MS e a produção de etanol das silagens, enquanto o tratamento com hidróxido de sódio diminuiu a produção de etanol, mas não melhorou a qualidade nutritiva nem reduziu as perdas de MS. Esses autores concluíram que a utilização de inoculante microbiano contendo Lactobacillus plantarum não melhorou a qualidade nutritiva da silagem.

A utilização de aditivos microbiológicos em silagem de cana-de-açúcar também foi estudada por Pedroso (2003), que, com a adição de Lactobacillus buchneri (3,64 x $10^{5} \mathrm{ufc/g}$ de materia verde), observou diminuição da perda total de MS da silagem, mas não notou redução no teor de etanol produzido.

Este estudo foi realizado para quantificar o teor de carboidratos solúveis presentes na cana-de-açúcar que anula a produção de etanol. Considerou-se que, diminuindo o teor de carboidratos solúveis, o desenvolvimento de leveduras seria prejudicado, resultando em menor teor de etanol na silagem. Avaliaram-se ainda os efeitos dos teores de carboidratos solúveis sobre as características nutricionais e fermentativas e sobre as perdas de MS e a estabilidade aeróbia das silagens.

\section{Material e Métodos}

O experimento foi realizado nas dependências do Departamento de Nutrição e Produção Animal da Faculdade de Medicina Veterinária e Zootecnia da Universidade de São Paulo (Campus de Pirassununga). Após a colheita manual da cana-de-açúcar, separou-se o caule das folhas. O caule foi passado duas vezes em engenho de cana com motor elétrico - marca MAQTRON, modelo B728, potência $1 / 3 \mathrm{CV}$, voltagem 220 e capacidade $60 \mathrm{~L} /$ hora - para retirada do caldo. Em seguida, o bagaço (caule sem o caldo) foi misturado às folhas e submetido à picagem (Picadora - marca Nogueira, modelo EM-9F3B) em fragmentos médios de $1,55 \mathrm{~cm}$. A avaliação do tamanho médio de partículas foi realizada de acordo com a metodologia das peneiras do "PennState Particle Size Separator", proposto por Lammers et al. (1996).

No primeiro tratamento, o caldo retirado foi retornado em sua totalidade ao bagaço + folhas picados; no segundo tratamento, a cana foi reconstituída com metade do caldo e metade de água; e, no terceiro tratamento, apenas água foi retornada ao bagaço e às folhas. Cálculos de rendimento comprovaram que $63,60 \%$ do peso da cana correspondeu às folhas e ao bagaço e 36,4\% correspondeu ao caldo. Com os dados de MS dessas duas frações, os cálculos foram elaborados retornando com água em quantidade correspondente ao conteúdo de líquido retirado, mantendo-se dessa forma teores iguais de MS entre os tratamentos. Os cálculos foram realizados com base nos dados de MS do caldo e do bagaço + folhas obtidos na cana-de-açúcar amostrada 15 dias antes no intuito de diminuir os teores de carboidratos solúveis na cana sem alterar os teores de MS, que foram mantidos estáveis.

Utilizaram-se 12 silos experimentais confeccionados com baldes plásticos de $252 \mathrm{~mm}$ de altura e $245 \mathrm{~mm}$ de diâmetro (6 litros de capacidade). Imediatamente após a preparação dos tratamentos, as respectivas massas foram colocadas dentro de cada silo e compactadas a densidade de $500 \mathrm{~kg}$ de silagem $/ \mathrm{m}^{3}$. Os silos foram fechados com tampas, pesados, armazenados verticalmente em local abrigado e abertos somente após 85 dias de estocagem. Antes da abertura, os silos foram pesados para determinação das perdas de MS por fermentação, calculadas como a diferença entre os pesos das massas obtidos no enchimento e na abertura dos silos multiplicados pelos respectivos teores de MS. Finalmente, as perdas foram transformadas em porcentagem da massa inicial.

As análises foram conduzidas no Laboratório de Nutrição e Produção Animal da Faculdade de Medicina Veterinária e Zootecnia da USP. Os silos foram abertos e as massas foram homogeneizadas e uma parcela foi separada para determinação dos teores de MS (a 65 e $105^{\circ} \mathrm{C}$ em estufa de circulação forçada); proteína bruta (PB), segundo AOAC (1980); fibra em detergente neutro (FDN); fibra em detergente ácido (FDA); e lignina, segundo Van Soest et al. (1991).

Os carboidratos solúveis (CHOs) foram determinados de acordo com a metodologia de Johnson et al. (1966), o amido segundo Pereira \& Rossi (1995) - técnica modificada para prévia extração dos carboidratos solúveis segundo Hendrix (1993) - e o nitrogênio insolúvel em detergente ácido (NIDA), segundo Van Soest \& Robertson (1985). Outra fração foi congelada imediatamente para futura contraprova e outra, ainda, foi colocada em prensa manual para extração do suco. 
Imediatamente após a prensagem do material, $50 \mathrm{~mL}$ de suco de silagem foram utilizados para determinação do $\mathrm{pH}$ em potenciômetro digital de mesa (marca Procyon, modelo 310), calibrado com soluções tampão de pH 4,0 e 7,0.

A determinação dos ácidos orgânicos e do etanol contidos no suco da silagem foi realizada por cromatografia gasosa, segundo método preconizado por Erwin et al. (1961), utilizando-se cromatógrafo a gás (marca Finnigan, modelo 9001) equipado com coluna de vidro de sílica MEGABOR (marca Ohio Valley, modelo OV-351) de $30 \mathrm{~m} \mathrm{x}$ 0,53 mm e fase estacionária de 1,0 mícron. As determinações foram realizadas injetando-se 1,0 microlitro de amostra ao cromatógrafo - integrado ao computador que processava os cálculos de quantificação por meio do programa computacional Borwin (versão 1.21) - para cromatografia utilizando-se a solução-padrão como base para o cálculo das concentrações de ácidos orgânicos da amostra. O número de repetições por amostra foi o necessário para que a diferença entre leituras fosse inferior a 5\%. A solução-padrão foi injetada a cada dez injeções sucessivas de amostras visando evitar possíveis distorções das leituras com a contaminação da coluna. Os cálculos das concentrações dos ácidos orgânicos foram realizados em micro-computador comparando-se as amostras à soluçãopadrão.

Ainda durante a coleta de amostras, alíquotas de $2 \mathrm{~mL}$ de suco de silagem foram colocadas em tubos de ensaio contendo $1 \mathrm{~mL}$ de solução de ácido sulfúrico $1 \mathrm{~N}$ e armazenadas sob refrigeração até as análises de nitrogênio amoniacal, que foram realizadas por colorimetria, segundo método proposto por Kulasek (1972) e adaptado por Foldager (1977). As leituras em absorbância foram realizadas em espectrofotômetro (marca Beijing Rayleigh AIC modelo VIS-7220) regulado em $630 \mathrm{~nm}$. Os valores de absorbância foram utilizados para calcular as concentrações de nitrogênio amoniacal em mg de $\mathrm{N}-\mathrm{NH}_{3} / 100 \mathrm{~mL}$, pela equação de regressão linear obtida pela calibração do aparelho com soluções-padrão de diferentes concentrações.

A digestibilidade in vitro de MS (DIVMS) foi determinada segundo Tilley \& Terry (1963) por meio da pesagem de $0,5 \mathrm{~g}$ de amostra pré-seca em tubos de centrífuga previamente secos e calibrados. Aos tubos foram adicionados $40 \mathrm{~mL}$ de solução de McDougall (saliva artificial) e $10 \mathrm{~mL}$ de inóculo de rúmen de animais mantidos em pastagem de capim-braquiária com sal mineral no cocho. Os tubos foram vedados com rolhas de borracha contendo válvula de bunsen (imediatamente depois de passar $\mathrm{CO}_{2}$ ) e incubados por 48 horas em estufa de temperatura controlada, onde foram agitados pelo menos 3 a 4 vezes durante a fermentação. A segunda fase ocorreu após centrifugação e descarte do sobrenadante. Uma solução de pepsina (1:10.000) foi adicionada ( $50 \mathrm{~mL}$ ) a $0,2 \%$ em cada tubo, agitando-os e colocando-os em estufa a $39^{\circ} \mathrm{C}$ por mais 48 horas. Após lavagem, secagem e pesagem dos tubos, foram realizados os cálculos segundo a fórmula a seguir:

100 x g de MS na amostra - (g de MS residual - g de MS do branco)

DIVMS $=$

g de MS da amostra

A determinação da estabilidade aeróbia da silagem foi realizada utilizando-se aproximadamente 2,0 kg de massa úmida retirados de cada balde, transferidos para caixa de isopor com capacidade de 12 litros e armazenados em local coberto com temperatura controlada a $25^{\circ} \mathrm{C}$. As temperaturas das silagens foram obtidas a cada hora, durante 14 dias, por meio de sistema de monitoração e aquisição de dados (SIMAD), composto por 12 sensores de temperatura, 2 módulos de aquisição de dados, 1 conversor de rede e 1 software para monitoramento, aquisição e controle de variáveis ambientais (MACVA, versão 1.2, da AUTSENS Indústria e Comércio de Equipamentos Eletrônicos). Adicionalmente, foram avaliadas as temperaturas máximas alcançadas $\left({ }^{\circ} \mathrm{C}\right)$, o tempo (em horas) necessário para alcançá-las e o tempo para elevação dessas temperaturas em $2^{\circ} \mathrm{C}$ (em horas). A estabilidade aeróbia foi calculada como taxa de elevação de temperatura utilizando-se a temperatura máxima observada dividida pelo tempo necessário para a silagem atingir essa temperatura (Ruppel et al., 1995).

Utilizou-se delineamento inteiramente casualizado com três tratamentos, cada um com quatro repetições. Os tratamentos consistiram da adição de água nos níveis 0\% ( $100 \%$ de caldo), $50 \%$ ( $50 \%$ de caldo) e $100 \%$ ( $0 \%$ de caldo) às folhas + bagaço. Os dados foram analisados por meio do programa computacional Statistical Analysis System (SAS, 1998), verificando-se anteriormente a normalidade dos resíduos pelo teste de Shapiro-Wilk (PROC UNIVARIATE). Os dados (variável dependente) que não atenderam a esta premissa foram submetidos à transformação logarítmica $[\log (\mathrm{X}+1)]$ ou pela raiz quadrada $[R Q(X+1 / 2)]$. Os dados originais ou transformados, quando o procedimento de transformação foi necessário, foram submetidos à análise de regressão polinomial pelo procedimento GLM decompondo-se os efeitos em lineares e desvio da linearidade. 


\section{Resultados e Discussão}

Os teores de MS e carboidratos solúveis das silagens (Tabela 1) foram maiores que os observados por Coan et al. (2005), de $27 \%$ de MS e $17 \%$ de CHOs. A porcentagem de MS não se manteve constante como desejado, provavelmente em virtude da diferença entre o material previamente amostrado para cálculo de MS e o material processado no dia da ensilagem. Entretanto, o teor de carboidratos solúveis diminuiu de 41,6\% para 34,0 e 23,0\% na cana-de-açúcar fresca com 0, 50 e 100\% de substituição do caldo por água.

A substituição do caldo da cana por água teve efeito linear $(\mathrm{P}<0,05)$ decrescente nos teores de MS da silagem (Tabela 2), o que não era esperado, pois procurou-se manter o mesmo teor de MS, mesmo após a substituição do caldo pela água. Esses resultados corroboram os obtidos por Woolford (1984), que sugeriu teores de MS de 25 a 28\% para se obter silagem de boa qualidade.

Os teores de FDA, FDN e lignina aumentaram de forma linear $(\mathrm{P}<0,05)$ pela substituição do caldo da cana por água. Os maiores valores foram obtidos nas silagens de cana com $100 \%$ de água na reconstituição. De acordo com Van Soest (1994), a análise de FDN permite estimar as concentrações totais de celulose, hemicelulose e lignina da parede celular e a análise de FDA representa a estimativa do teor total de celulose e de lignina da amostra. Com o aumento das frações fibrosas, a digestibilidade in vitro da MS diminuiu de forma linear decrescente $(\mathrm{P}<0,05)$.

$\mathrm{O}$ teor de carboidratos solúveis diminuiu de forma linear $(\mathrm{P}<0,05)$ com a substituição de caldo por água. Com a adição de $0 \%$ de água, houve desaparecimento de $75 \%$ dos CHOs, enquanto, com a adição de 50\% de água, o teor de

Tabela 1 - Composição bromatológica da cana-de-açúcar fresca

\begin{tabular}{lrrrr}
\hline \multicolumn{4}{c}{ Cana-de-açúcar } \\
\cline { 2 - 5 } & Cana in natura & 0\% água & $50 \%$ água & $100 \%$ água \\
\hline MS & 36,23 & 34,04 & 33,01 & 29,13 \\
PB & 2,59 & 2,24 & 2,35 & 2,79 \\
NIDA & 30,09 & 34,24 & 36,61 & 27,02 \\
FDA & 34,46 & 31,08 & 35,40 & 40,99 \\
FDN & 57,68 & 53,40 & 60,65 & 69,98 \\
Lignina & 5,62 & 5,67 & 6,68 & 7,16 \\
Amido & 0,22 & 0,22 & 0,19 & 0,14 \\
CHOs & 41,14 & 41,63 & 34,04 & 22,98 \\
DIVMS & 52,96 & 56,94 & 53,15 & 45,63 \\
P T & 9,22 & 9,26 & 7,71 & 7,74 \\
\hline
\end{tabular}

MS: matéria seca total (\%); PB: proteína bruta (\% MS); NIDA: nitrogênio insolúvel em detergente ácido (\% do $\mathrm{N}$ total); FDA: fibra em detergente ácido (\% MS); FDN: fibra em detergente neutro (\% MS); lignina (\% MS); amido (\% MS); $\mathrm{CHOs:} \mathrm{carboidratos} \mathrm{solúveis} \mathrm{( \%} \mathrm{MS);} \mathrm{DIVMS:} \mathrm{digestibilidade}$ in vitro da matéria seca (\% MS); e PT: poder tampão (meq./100 g MS de forragem).
CHOs diminuiu 79\% e, com a adição de 100\% de água, a redução foi de $81 \%$. Esses resultados são superiores aos relatados por Pedroso (2003), que, avaliando a silagem de cana-de-açúcar aos 12 meses de crescimento, observou desaparecimento de $68,0 \%$ dos carboidratos solúveis presentes no início da ensilagem. Alli et al. (1982), em pesquisa com cana-de-açúcar ensilada em tambores de 205 litros, observaram teor de CHOs de apenas 1,3\% da MS, teor de MS de $33 \%$ e de etanol de $9 \%$ da MS.

Houve desvio da linearidade $(\mathrm{P}<0,05)$ para os teores de $\mathrm{PB}$ e amido, embora as diferenças encontradas para $\mathrm{PB}$ tenham sido pequenas. Ressalta-se que a cana-de-açúcar é uma forrageira com baixa quantidade de proteína, em torno de $3 \%$, o que torna necessária a adição de outras fontes de nitrogênio quando se utiliza silagem de cana na alimentação animal.

Não foram observados resultados significativos para as variáveis poder tampão e nitrogênio insolúvel em detergente ácido (NIDA). De acordo com a literatura (Vilela 1998; Rodrigues et al., 2004), os teores de NIDA refletem a ocorrência da reação de Mayllard, que promove a complexação do nitrogênio à fibra, especialmente a hemicelulose, ocasionando diminuição do valor nutritivo da silagem por meio da indisponibilização de nitrogênio para o aproveitamento pelo animal. Esse fenômeno freqüentemente é observado na presença de calor e umidade, entretanto, esse complexo não se formou durante o processo de fermentação, uma vez que a planta fresca já possuía alta porcentagem de nitrogênio ligado à fibra.

Os teores de etanol foram reduzidos de forma linear $(\mathrm{P}<0,05)$ com a restituição da cana com água, o que está relacionado à menor metabolização dos $\mathrm{CHOs}$ a etanol pelas leveduras. Os resultados obtidos com reconstituição de $100 \%$ de água foram próximos aos encontrados por Bernardes et al. (2002), que ensilaram cana-de-açúcar aos 12 meses, quando o teor de CHOs está em torno de $23 \%$ na MS (Pedroso et al., 2005), e verificaram teor de 6,8\% de etanol na MS. Este teor está abaixo do encontrado no presente estudo, quando comparando ao tratamento onde a reconstituição foi feita com $50 \%$ de água (teor de etanol de 10,7\% na MS), correspondente ao nível de 34\% de CHOs na cana-de-açúcar antes da ensilagem. Neste experimento, a fermentação alcoólica da silagem foi mais intensa que o observado por Alli et al. (1982) em cana-de-açúcar ensilada com 28\% de MS e $52 \%$ de CHOs. Esses autores verificaram estabilização no teor de etanol em 9,0\% da MS no sexto dia de ensilagem.

Efeito linear $(\mathrm{P}<0,05)$ crescente foi observado também para os teores de ácido acético. Pedroso (2003) afirmou que 
Tabela 2 - Composição bromatológica das silagens

\begin{tabular}{|c|c|c|c|c|c|c|c|c|c|}
\hline Variável & \multicolumn{3}{|c|}{ Tratamento } & Média & $\mathrm{CV}$ & \multicolumn{2}{|c|}{ Probabilidade } & Equação & $\mathrm{R}^{2}$ \\
\hline MS & 27,57 & 26,22 & 24,57 & 26,12 & 5,15 & 0,0001 & 0,6144 & $\hat{\mathrm{Y}}=27,620-0,029 \mathrm{x}$ & 0,9007 \\
\hline NIDA & 30,36 & 34,35 & 32,21 & 32,31 & 9,28 & 0,3625 & 0,0992 & - & - \\
\hline FDA & 46,69 & 49,56 & 54,77 & 50,34 & 7,71 & 0,0002 & 0,3329 & $\hat{\mathrm{Y}}=46,299+0,080 \mathrm{x}$ & 0,8104 \\
\hline Amido & 4,38 & 2,09 & 1,16 & 2,54 & 56,92 & 0,0001 & 0,0096 & $\hat{Y}=4,385-0,059 x+0,000273 x^{2}$ & 0,9792 \\
\hline CHOs & 10,79 & 7,27 & 4,21 & 7,42 & 43,52 & 0,0005 & 0,8399 & $\hat{\mathrm{Y}}=10,707-0,065 \mathrm{x}$ & 0,7560 \\
\hline DIVMS & 45,41 & 42,79 & 38,55 & 42,25 & 7,52 & 0,0001 & 0,3415 & $\hat{Y}=45,680-0,068 x$ & 0,8592 \\
\hline $\mathrm{PT}$ & 18,78 & 16,81 & 16,65 & 17,42 & 10,32 & 0,5190 & 0,3928 & - & - \\
\hline
\end{tabular}

MS: matéria seca total (\%); PB: proteína bruta (\% MS); NIDA: nitrogênio insolúvel em detergente ácido (\% do N total); FDA: fibra em detergente ácido (\% MS); FDN: fibra em detergente neutro (\% MS); lignina (\% MS); amido (\% MS); CHOs: carboidratos solúveis (\% MS); DIVMS: digestibilidade in vitro da matéria seca (\% MS); PT: poder tampão (meq./100 g MS de forragem); CV: coeficiente de variação (\%); linear: probabilidade para efeito linear; Desvio: probabilidade para efeito de desvio da linearidade.

esse ácido tem poder fungicida, o que acarretaria diminuição na quantidade de leveduras na produção de álcool. Nas três condições avaliadas nesta pesquisa, o nível de ácido acético foi superior ao de $0,8 \%$ proposto por Silveira (1987) como aceitável. Verificou-se aumento não linear $(\mathrm{P}<0,05)$ do teor do ácido propiônico com a diminuição dos carboidratos solúveis, o que de certa forma pode ser favorável, uma vez que as bactérias produtoras de ácido propiônico são avaliadas como colaboradoras da estabilidade aeróbia das silagens, pois competem com as leveduras epífitas (McDonald et al., 1991).

Os teores de ácido butírico foram influenciados de forma linear decrescente $(\mathrm{P}<0,05)$ pela redução do teor de CHOs da cana. Portanto, é possível que bactérias indesejáveis, como Clostridium sp., não estavam presentes nas silagens confeccionadas, uma vez que a produção de ácido butírico foi baixa nas três situações. Segundo Silveira (1987), esse resultado indica que as transformações indesejáveis não ocorreram na massa ensilada. Na cana-deaçúcar, não se espera aumento do teor de ácido butírico, uma vez que essa forrageira possui excesso de carboidratos solúveis, o que favorece a fermentação lática e alcoólica.

O teor de ácido lático reduziu de forma linear $(\mathrm{P}<0,05)$ e, mesmo com a adição de $0 \%$ de água, ou seja, mantendo o teor de CHOs bem próximo do original, o teor deste ácido não atingiu o valor mínimo de 3,0\% proposto por Vilela (1990) para caracterizar uma silagem de boa qualidade. Segundo Vilela (1998), silagens de boa qualidade possuem altas porcentagens de ácido lático e baixo teor (ou nulo) de ácido butírico. Observou-se efeito linear $(\mathrm{P}<0,05)$ da redução dos teores de CHOs sobre os teores de $\mathrm{N}-\mathrm{NH}_{3}$, resultado não satisfatório, de acordo com Silveira (1987), que, sintetizando relatos de diversos autores, afirmou que silagens de boa qualidade apresentam valores de nitrogênio amoniacal de no máximo 8,0\% do nitrogênio total.

A diminuição do teor de carboidratos da silagem promoveu efeito linear $(P<0,05)$ decrescente sobre a relação lático:acético, o que pode indicar piora no perfil fermentativo das silagens. Na relação ácidos:etanol, houve desvio da linearidade $(\mathrm{P}<0,05)$ e melhora na relação com $100 \%$ de reconstituição de água, uma vez que, neste caso, a quantidade de etanol produzida foi significativamente menor. Também houve efeito linear $(\mathrm{P}<0,05)$ crescente sobre a relação lático:etanol, indicando maior fermentação lática que alcoólica quando a quantidade de $\mathrm{CHOs} \mathrm{diminuiu.}$ Entretanto, houve efeito linear $(\mathrm{P}<0,05)$ decrescente sobre a relação lático:acético com a diminuição do teor de CHOs da silagem, o que pode indicar piora no perfil de fermentação ácida, apesar da melhora na fermentação alcoólica.

Observou-se efeito linear $(\mathrm{P}<0,05)$ crescente da diminuição dos teores de $\mathrm{CHOs}$ sobre o $\mathrm{pH}$, que ficou um pouco abaixo dos valores aceitáveis $(3,7$ a 4,2). Chamberlain (1987) postulou que a rápida acidificação decorrente da produção de ácido lático poderia favorecer o desenvolvimento de leveduras não-sensíveis ao baixo $\mathrm{pH}$ e, assim, promover a fermentação de açúcares residuais a etanol. Segundo esse autor, a produção de etanol se iniciaria depois de terminada a fermentação lática, entretanto, os dados deste estudo comprovam que a fermentação alcoólica ou a fermentação acética competem com a fermentação lática, uma vez que a produção de ácido lático diminuiu com a substituição de caldo por água, mesmo com grande quantidade de carboidratos solúveis residuais, portanto, houve menor acidificação do meio.

Efeito linear $(\mathrm{P}<0,05)$ também foi observado para as perdas de MS com a diminuição do teor de CHOs. Com a 
Tabela 3 - Perfil fermentativo das silagens

\begin{tabular}{|c|c|c|c|c|c|c|c|c|c|}
\hline \multirow[b]{2}{*}{ Variável } & \multicolumn{3}{|c|}{ Tratamento } & \multirow[b]{2}{*}{ Média } & \multirow[b]{2}{*}{$\mathrm{CV}$} & \multicolumn{2}{|c|}{ Probabilidade } & \multirow[b]{2}{*}{ Equação } & \multirow[b]{2}{*}{$\mathrm{R}^{2}$} \\
\hline & $0 \%$ água & $50 \%$ água & $100 \%$ água & & & Linear & Desvio & & \\
\hline Etanol & 15,33 & 10,77 & 5,58 & 10,56 & 40,01 & 0,0001 & 0,5455 & $\hat{\mathrm{Y}}=15,435-0,097 \mathrm{x}$ & 0,9691 \\
\hline Acético & 1,71 & 2,75 & 4,08 & 2,85 & 36,58 & 0,0001 & 0,3884 & $\hat{\mathrm{Y}}=1,6645+0,023 \mathrm{x}$ & 0,9455 \\
\hline Propiônico & 0,06 & 0,38 & 1,14 & 0,53 & 90,88 & 0,0001 & 0,0082 & $\hat{Y}=0,061+0,00223 x+0,0000858 x^{2}$ & 0,9620 \\
\hline Butírico & 0,12 & 0,08 & 0,03 & 0,08 & 49,38 & 0,0001 & 0,6644 & $\hat{\mathrm{Y}}=0,130-0,000945 \mathrm{x}$ & 0,9673 \\
\hline Lático & 2,50 & 2,25 & 1,31 & 2,02 & 30,31 & 0,0007 & 0,1314 & $\hat{\mathrm{Y}}=2,618-0,011 \mathrm{x}$ & 0,7563 \\
\hline Relação & 1,47 & 0,82 & 0,32 & 0,87 & 59,71 & 0,0001 & 0,5709 & $\hat{\mathrm{Y}}=1,453-0,011 \mathrm{x}$ & 0,8820 \\
\hline lático:acético & & & & & & & & & \\
\hline $\begin{array}{l}\text { Relação } \\
\text { ácidos:etanol }\end{array}$ & 0,28 & 0,51 & 1,18 & 0,66 & 61,17 & 0,0001 & 0,0016 & $\hat{Y}=0,288-0,00001036 x+0,000089 x^{2}$ & 0,8189 \\
\hline $\begin{array}{l}\text { Relação ácido } \\
\text { lático:etanol }\end{array}$ & 0,16 & 0,21 & 0,23 & 0,20 & 21,50 & 0,0163 & 0,6251 & $\hat{Y}=0,167+0,00071 x$ & 0,4985 \\
\hline $\mathrm{N}-\mathrm{NH}_{3}$ & 10,12 & 11,91 & 12,50 & 11,51 & 11,74 & 0,0057 & 0,3278 & $\hat{\mathrm{Y}}=10,319+0,023 \mathrm{x}$ & 0,6105 \\
\hline $\mathrm{pH}$ & 3,36 & 3,37 & 3,44 & 3,39 & 1,682 & 0,0279 & 0,3138 & $\hat{Y}=3,350+0,00085 x$ & 0,4703 \\
\hline Perdas & 19,98 & 19,80 & 11,51 & 17,10 & 29,28 & 0,0041 & 0,0636 & $\hat{\mathrm{Y}}=21,335+0,084 \mathrm{x}$ & 0,6794 \\
\hline
\end{tabular}

Etanol (\% MS); ácido acético (\% MS); ácido propiônico (\% MS); Butírico (\% MS); Lático (\% MS); N-NH de matéria seca (\% MS); CV: coeficiente de variação (\%); Linear: probabilidade para efeito linear; Desvio: probabilidade para efeito do desvio da linearidade.

Tabela 4 - Estabilidade aeróbia das silagens

\begin{tabular}{|c|c|c|c|c|c|c|c|c|c|}
\hline \multirow[b]{2}{*}{ Variável } & \multicolumn{3}{|c|}{ Tratamento } & \multirow[b]{2}{*}{ Média } & \multirow[b]{2}{*}{$\mathrm{CV}$} & \multicolumn{2}{|c|}{ Probabilidade } & \multirow[b]{2}{*}{ Equação } & \multirow[b]{2}{*}{$\mathrm{R}^{2}$} \\
\hline & $0 \%$ água & 50\% água & $100 \%$ água & & & Linear & Desvio & & \\
\hline Tempo (h) & 95,25 & 159,75 & 189,25 & 148,08 & 30,32 & 0,0001 & 0,1922 & $\hat{\mathrm{Y}}_{\hat{1}}=101,083+0,940 \mathrm{x}$ & 0,8333 \\
\hline Máx $\left({ }^{\circ} \mathrm{C}\right)$ & 31,11 & 32,69 & 36,46 & 33,42 & 30,32 & 0,0001 & 0,1922 & $\hat{\mathrm{Y}}=30,75+0,053 \mathrm{x}$ & 0,8333 \\
\hline Taxa $\left({ }^{\circ} \mathrm{C} / \mathrm{h}\right)$ & 0,10 & 0,06 & 0,07 & 0,08 & 43,32 & 0,1987 & 0,2717 & - & - \\
\hline Tempo $2^{\circ} \mathrm{C}(\mathrm{h})$ & 15,75 & 15,75 & 16,50 & 16,00 & 3,76 & 0,0750 & 0,2752 & - & - \\
\hline
\end{tabular}

Tempo: tempo decorrido para alcançar a máxima temperatura (horas); Máx.: máxima temperatura alcançada ( $\left.{ }^{\circ} \mathrm{C}\right) ;$ Taxa: taxa de elevação da temperatura $\left({ }^{\circ} \mathrm{C} /\right.$ hora); Tempo $2^{\circ} \mathrm{C}(\mathrm{h})$ : tempo para elevação da temperatura em $2^{\circ} \mathrm{C}$; CV: coeficiente de variação (\%); Linear: probabilidade para efeito linear; Desvio: probabilidade para efeito de desvio da linearidade.

maior inclusão de água, as perdas diminuíram, como resultado da menor concentração de carboidratos solúveis, que não favoreceu tanto o desenvolvimento da população de leveduras com a diminuição da produção de etanol e, conseqüentemente, das perdas de MS. Segundo Ranjit \& Kung Jr. (2000), as leveduras presentes na silagem têm pH ótimo para desenvolvimento de aproximadamente 3,5\% e contribuem significativamente para o aumento nas perdas de MS.

Observou-se relação linear entre a substituição do caldo pela água e as concentrações de etanol na silagem (Figura 1). Quando os dados de concentrações de etanol na silagem foram submetidos à regressão em função do teor de CHOs, associado a cada tratamento, obteve-se a seguinte equação: Etanol $=-6,42+0,517 * \mathrm{CHO}\left(\mathrm{R}^{2}=0,9948\right)$. Portanto, cada unidade percentual de CHOs na planta resulta em 0,52 unidade percentual de etanol (com base na MS da silagem). Espera-se que a silagem tenha ausência de etanol $($ Etanol $=0)$ quando a cana-de-açúcar possui menos que 12,42\% de carboidratos solúveis (se Etanol = 0 , então $0=-6,42+0,517 * \mathrm{CHO} \Rightarrow \mathrm{CHO}=12,42 \%)$. Esse valor de $12,42 \%$ de CHOs que minimiza a produção de etanol foi muito inferior ao normalmente encontrado para essa forrageira, que, nesta pesquisa, foi igual a 41,63\%. Assim, conclui-se que dificilmente será possível obter silagens de cana-de-açúcar de boa qualidade utilizando-se apenas técnicas de manejo da cultura ou processamento da forragem durante a ensilagem.

Efeito linear crescente $(\mathrm{P}<0,05)$ foi observado para o tempo para alcançar a máxima temperatura e máxima temperatura alcançada (Tabela 4), embora nenhum efeito tenha sido observado sobre a taxa de elevação da temperatura ou sobre o tempo para elevação da temperatura em $2^{\circ} \mathrm{C}$ (Tempo $2^{\circ} \mathrm{C}$ ). De acordo com Muck \& Kung Jr. (1997), o aumento nas concentrações de ácido acético contribui para melhorar a estabilidade aeróbia após a abertura do silo. Neste estudo, esse aumento foi observado nas concentrações de ácido acético, porém, não é possível afirmar que melhorou a 


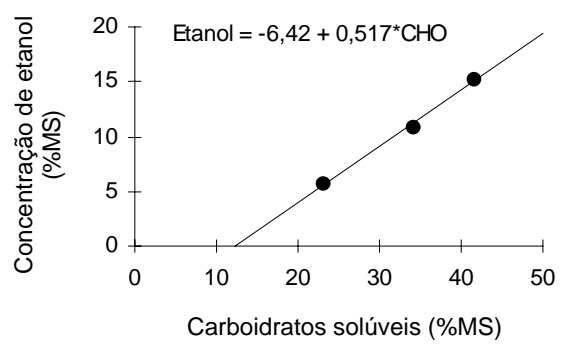

Figura 1 - Relação entre as concentrações de carboidratos solúveis da planta (\% da MS) e as concentrações de etanol na silagem (\% da MS).

estabilidade aeróbia da silagem. Assim, não foi possível comprovar neste experimento que os teores de CHOs alteram a estabilidade aeróbia da silagem.

\section{Conclusões}

Maiores concentrações de carboidratos solúveis são determinantes da produção de etanol em silagens de canade-açúcar. Nas condições experimentais testadas, a concentração de carboidratos solúveis na planta que anularia a produção de etanol na silagem é de 12,4\% da MS.

\section{Agradecimento}

Aos técnicos Ari de Castro, Gilson de Godoy e Simi Robassini, pelas análises laboratoriais, e aos funcionários Everson Lázaro e Gilmar Botteon, pela colaboração e prestatividade.

\section{Literatura Citada}

ALCÂNTARA, E.; AgUilerA, A.; Elliott, R. et al. Fermentation and utilization by lambs of sugarcane harvest fresh and ensiled with and without $\mathrm{NaOH}$ : 4. Ruminal kinetcs. Animal Feed Science and Technology, v.23, n.4, p.323331, 1989.

ALLI, I.; BAKER, B.E.; GARCIA, G. Studies of the fermentation of chopped sugarcane. Animal Feed Science and Technology, v.7, n.4, p.411-417, 1982.

ALLI, I.; FAIRBAIRN, R.; BAKER, B.E. et al. The effects of ammonia on the fermentation of chopped sugarcane. Animal Feed Science and Technology, v.9, n.4, p.291-299, 1983.

ASSOCIATION OF OFFICIAL ANALYTICAL CHEMISTS - AOAC. Official methods of analysis. 10.ed. Washington, D.C.: 1980. $1015 p$.

BERNARDES, T.F.; SILVEIRA, R.N.; COAN, R.M. et al. Características fermentativas e presença de levedura na canade-açúcar crua ou queimada ensilada com aditivo In: REUNIÃO ANUAL DA SOCIEDADE BRASILEIRA DE ZOOTECNIA, 39., 2002. Recife. Anais... Recife: Sociedade Brasileira de Zootecnia, 2002. (CD-ROM).
CHAMBERLAIN, D.G. The silage fermentation in relation to the utilization of nutrients in the rumen. Process Biochemistry, v.4, n.1, p.60-63, 1987.

COAN, R.M.; VIEIRA, P.F.; SILVEIRA, R.N. et al. Inoculante enzimático-bacteriano, composição química e parâmetros fermentativos das silagens dos capins tanzânia e mombaça. Revista Brasileira de Zootecnia, v.34, n.2, p.416-424, 2005.

ERWIN, E.S.; MARCO, G.J.; EMERY, E.M. Volatile fatty acid analyses of blood and rumen fluid by gas chromatography. Journal of Dairy Science, v.44, n.9, p.1768-1771, 1961.

FOLDAGER, J. Protein requirement and non protein nitrogen for high producing cow in early lactation. Michigan: Michigan State University, 1977. Thesis (Ph D. in Animal Science) - Michigan State University, 1977.

FREITAS, A.W.P.; PEREIRA, J.C.; ROCHA, F.C. et al. Características da silagem de cana-de-açúcar tratada com inoculante bacteriano e hidróxido de sódio e acrescida de resíduo da colheita de soja Revista Brasileira de Zootecnia, v.35, n.1, p.48-59, 2006.

HENDRIX, D.L. Rapid extraction and analysis of nonstructural carbohydrates in plant tissues. Crop Science, v.33, n.6, p.13061311, 1993.

JOHNSON, R.R.; BALWANI, T.L.; JOHNSON, L.J. et al. Corn plant maturity. Effect on in vitro cellulose digestibility and soluble carbohydrate content. Journal of Animal Science, v.25, n.2, p.617-623, 1966.

KULASEK, G. A micromethod for determination of urea in plasma, whole blood and blood cells using urease and phenol reagent. Polish Archiwun Weterynaryjne, v.15, n.4, p.801-810, 1972.

LAMMERS, B.P.; BUCKMASSTER, D.R.; HEINRICHS, E.J. A simple method for the analysis of particle sizes of forages and total mixed rations. Journal of Dairy Science, v.79, n.5, p.922-928, 1996.

McDONALD, P.; HENDERSON, A.R.; HERON, S.J.E. The biochemistry of silage. Marlow: Chalcombe Publications, 1991. 226p.

MUCK, R.E.; KUNG JR., L. Effects of silage additives on ensiling. In: SILAGE: FIELD TO FEEDBUNK NORTH AMERICA CONFERENCE, 1997, Hershey. Proceedings... Hershey: NRAES, 1997. p.187-199.

PEDROSO, A.F. Aditivos químicos e microbianos no controle de perdas e na qualidade de silagem de cana-de-açúcar (Saccharum officinarum L.). Piracicaba: Escola Superior de Agricultura "Luiz de Queiroz”, 2003. 120p. Dissertação (Doutorado em Agronomia) - Escola Superior de Agricultura "Luiz de Queiroz", 2003.

PEDROSO, A.F.; NUSSIO, L.G.; PAZIANI, S.F. et al. Fermentation and epiphytic microflora dynamics in sugarcane silage. Scientia Agricola, v.62, n.5, p.427-432, 2005.

PEREIRA, J.R.A.; ROSSI JR., P. Manual prático de avaliação nutricional de alimentos. 1.ed. Piracicaba: Fundação de Estudos Agrários Luiz de Queiroz, 1995. 25p.

RANJIT, N.K.; KUNG JR., L. The effects of Lactobacillus buchneri, Lactobacillus plantarum, or a chemical preservative on the fermentation and aerobic stability of corn silage. Journal of Dairy Science, v.83, n.3, p.526-535, 2000.

RODRIGUES, P.H.M.; ALMEIDA, L.F.S.; LUCCI, C.S. et al. Efeito da adição de inoculantes microbianos sobre o perfil fermentativo da silagem de alfafa adicionada de polpa cítrica. Revista Brasileira de Zootecnia, v.33, n.6, p.1646-1653, 2004.

RUPPEL, K.A.; PITT, R.E.; CHASE, L.E. et al. Bunker silo management and its relationship to forage preservation on dairy farms. Journal of Dairy Science, v.78, n.1, p.141153, 1995.

SCHEFFER DE ROJAS, S.M. Efeitos de aditivos e do momento de vedação na qualidade da silagem de milho em condições de laboratório. Belo Horizonte: Universidade Federal de Minas Gerais, 1976. 83p. Dissertação (Mestrado em Zootecnia) Universidade Federal de Minas Gerais, 1976. 
SILVEIRA, A.C. Produção e utilização de silagens. In: SEMANA DE ZOOTECNIA, 12., 1987, Pirassununga. Anais... Pirassununga: Fundação Cargill, 1987. p.119-134.

STATISTICAL ANALYSIS SYSTEM - SAS. SAS User's guide: statistics. 7.ed. Cary: SAS Institute, 1998. (CD-ROM).

TILLEY, J.M.A.; TERRY, R.A. A two-stage technique for the in vitro digestion of forage crops. Journal of British Grassland Society, v.18, n.2, p.104-11, 1963.

Van SOEST, P.J.; ROBERTSON, J.B. Analysis of forages and fibrous foods. 3.ed. Ithaca: Cornell University, 1985. 202p.

Van SOEST, P.J.; ROBERTSON, J.B.; LEWIS, B.A. Symposium: Carbohydrate metodology, metabolism, and nutritional implications in dairy cattle. Methods for dietary fiber, neutral detergent fiber, and nonstarch polysaccharides in relation to animal nutrition. Journal of Dairy Science, v.74, n.1, p.35833597, 1991.

Van SOEST, P.J. Nutritional ecology of the ruminant. 2.ed. Ithaca: Cornell University Press, 1994. 476p.

VILELA, D. Utilização do capim-elefante na forma de forragem conservada. In: SIMPÓSIO SOBRE CAPIM-ELEFANTE, 1990, Coronel Pacheco. Anais... Coronel Pacheco: EMBRAPA Centro Nacional de Pesquisa de Gado de Leite, 1990. p.89-131.

VILELA, D. Aditivos para silagem. In: REUNIÃO ANUAL DA SOCIEDADE BRASILEIRA DE ZOOTECNIA, 35., 1998, Botucatu. Anais... Botucatu: Sociedade Brasileira de Zootecnia, 1998. p.73-108.

WOOLFORD, M.K. The silage fermentation. New York: Marcel Dekker, 1984. v.14, 350p. 